Portland State University

PDXScholar

\title{
The Military Genogram: A Solution-Focused Approach for Resiliency Building in Service Members and Their Families
}

\author{
Eugenia Weiss \\ University of Southern California, Irvine, CA \\ Jose Coll \\ Portland State University, coll@pdx.edu \\ Jennifer Gerbauer \\ University of Southern California, Irvine, CA \\ Kate Smiley \\ University of Southern California, Irvine, CA \\ Ed Carillo \\ University of Southern California, Irvine, CA
}

Follow this and additional works at: https://pdxscholar.library.pdx.edu/socwork_fac

Part of the Military and Veterans Studies Commons, and the Social Work Commons

Let us know how access to this document benefits you.

\section{Citation Details}

Weiss, E. L., Coll, J. E., Gerbauer, J., Smiley, K., \& Carillo, E. (2010). The military genogram: A solutionfocused approach for resiliency building in service members and their families. The Family Journal, 18(4), 395-406.

This Article is brought to you for free and open access. It has been accepted for inclusion in Social Work Faculty Publications and Presentations by an authorized administrator of PDXScholar. Please contact us if we can make this document more accessible: pdxscholar@pdx.edu. 


\title{
The Military Genogram:
}

\section{A Solution-Focused Approach for Resiliency Building in Service Members and Their Families}

The Family Journal: Counseling and Therapy for Couples and Families 18(4) 395-406

(C) The Author(s) 2010

Reprints and permission sagepub.com/journalsPermissions.nav DOI: $10.1177 / 1066480710378479$ http://tfj.sagepub.com

(SAGE

\author{
Eugenia L. Weiss,' Jose E. Coll,' Jennifer Gerbauer,' Kate Smiley,' and \\ Ed Carillo'
}

\begin{abstract}
In recent decades, it has become evident among mental health practitioners that the military is a unique culture that is comprised of distinct ethics, core values, codes of conduct, and strict hierarchical roles. In light of the war in Afghanistan and the war in Iraq, veterans and their families are seeking mental health services due to a variety of psychosocial issues; however, mental health practitioners are lacking military-specific knowledge in understanding individuals within the military subculture. In addition, they are ill-equipped with interventions aimed at supporting the military family. Historically, the genogram has been an effective tool in delineating intergenerational family patterns that influence the functioning of the presenting client and his or her family. Therefore, this article proposes a military-specific genogram as an assessment and treatment instrument for the social worker to use with the client and his or her family to provide a comprehensive understanding of the military service member and his or her family. The application of the military genogram will be conducted in this article to demonstrate its utility and value. Furthermore, the genogram will encompass a solution-focused approach that promotes a strengths-based and resiliency perspective to be used with service members and their families.
\end{abstract}

\section{Keywords}

military genogram, military families, military culture, resiliency, solution-focused approach

Military personnel and their families make significant and life-altering sacrifices to maintain the safety and freedom of American citizens. Issues that face military personnel and their families include extended war zone deployments, relocation, financial, and caregiving burdens, soldier's combat stress as well as physical and psychological injury (Exum \& Coll, 2008). In light of the wars in Iraq and Afghanistan, veterans and their families are seeking mental health services for a variety of psychosocial issues; however, military-specific assessment and interventions aimed at supporting the military family are limited. Therefore, this article proposes the use of a military genogram as a tool to build therapeutic rapport and assist military personnel and the family in recognizing intergenerational patterns, identifying both barriers and strengths as well as developing individual and family growth. Embedded within the genogram will be a solution-focused perspective that will highlight family strengths and help build resiliency in the family and in the service member.

\section{Literature Review}

The genogram is a useful tool in understanding relationships and key events across generations; it is often used by a clinician as a family mapping diagram to recognize biological, psychological, and social patterns across time (Bowen, 1966; McGoldrick \& Gerson, 1985). Historically, the genogram was primarily designed for assessment purposes. However, the genogram has also been used to support the clinician in developing tailored intervention strategies for marriage and family therapy. For example, Foster, Jurkovic, Ferdinand, and Meadows (2002) used the genogram to assist married couples in identifying patterns within their families of origin and the impact of this history on their current marital relationship. In this example, the genogram was used to contextualize the couples' relationship and to create distinctiveness among partners to strengthen marital boundaries and develop authentic intimacy (Foster et al., 2002). The genogram has also been used with couples and families to assist them in understanding the meaning and function of

\footnotetext{
'School of Social Work, University of Southern California, Irvine, CA, USA

Corresponding Author:

Eugenia L. Weiss, School of Social Work, University of Southern California, 2300 Michelson, Irvine, CA 926I2, USA

Email: eugenia.weiss@usc.edu
} 
finances in addition to identifying the family's basic needs and resources (Duba, 2009; Mumford \& Weeks, 2003). Furthermore, in recent years, the genogram has incorporated variables such as cultural, spiritual, academic, occupational, and trauma-based domains.

\section{The Cultural and Spiritual Genogram}

Along with recognizing family relational patterns, the genogram is also used to assess cultural factors within the marriage and family context (Keiley, et al., 2002). Hardy and Laszloffy (1995) developed a cultural genogram to illustrate the influence of culture on the family system by encouraging discussions that reveal culturally based assumptions and stereotypes within families and assist in recognizing cultural identities for personal growth.

The cultural genogram has also been used to assist health care patients and their families by incorporating the elements of culture into their health care treatment (Sylvia, et al., 2007). Additionally, Selma (2008) developed a culture-specific genogram to help Mexican immigrants identify cultural protective factors and resources to adapt to a host culture. McCulloughChavis and Waites (2004) developed a genogram specific to African Americans to assist in identifying intergenerational history, values, principles, and spiritual traditions. Furthermore, Frame (2000) created a spiritually based genogram that was used as a "multigenerational map" of family religious and spiritual beliefs and the ensuing conflicts that developed out of familial religious differences. Hodge (2005) employed the use of a spiritual ecogram, a visual map of resources that can be used in conjunction with a genogram as an empowerment instrument to access client's strengths and help them overcome challenges. Thus, all of these culture-based genograms have been developed for the clinician to engage in culturally competent practice with a variety of clients.

\section{Occupational and Academic Genogram}

The genogram has also been used to identify the client's occupational and academic choices within the context of family values and intergenerational traditions (Magnuson, 2000). For instance, Kakiuchi and Weeks (2009) noted that family dialogue frequently influences occupational beliefs and the client's perception of his or her own abilities; this genogram focuses on the socioeconomic status of the family and its role in family member's work and career path choices. Granello, Hothersall, and Osborne (2000) developed an academic-specific genogram for students who were considering an advanced degree by identifying academic lineage and family themes as influential factors in the student's professional development.

\section{Genogram for Social Work and Health Care Training}

Genograms also serve as an educational device for students training in the health care professions (Shellenberger et al., 2007). For instance, the Family Therapy Institute pioneered a curriculum that included genogram work to educate students on how to be culturally sensitive toward clients who originate from various cultures, ethnicities, races, and religions. This training equipped the students to examine their own family backgrounds and belief systems through the use of the genogram to demonstrate how these issues can affect the therapeutic process (Shellenberger et al., 2007). The students were also encouraged to identify their own culturally based protective and risk factors, such as spirituality or family influence and the impact of these factors in working with clients.

\section{Trauma-Related Genograms}

More recently, mental health professionals have been developing genograms to help clients identify trauma. For instance, Karin (2006) developed a trauma-specific genogram to assist clients who have acute stress disorder (ASD) and posttraumatic stress disorder (PTSD). Additionally, Jordan (2004) used the genogram to educate individuals on traumatic family patterns such as multiple traumatic events in childhood like sexual abuse and domestic violence as well as dual couple trauma where each individual in a marriage has a history of child abuse. Other family traumas were examined as well, such as those that affect multiple family members, such as, fires, hurricanes, or natural disasters.

Dekel and Goldblatt (2008) conducted a literature review examining intergenerational transmission of trauma between fathers and sons based on a model that was originally designed to study the family members of Holocaust survivors. The purpose of the review was to investigate whether the transmission of trauma or "secondary traumatization" occurs in families of war veterans who suffer from symptoms of PTSD. The authors found that not all children of war veterans experience secondary traumatization. Kuehl (1995) argued that a genogram could be an effective tool for delineating the social and cultural factors that increase or minimize the potential for transmission of trauma between family members. Thus, a genogram can serve not only to identify risk factors but also to isolate protective factors that mitigate distress or reduce the possibility of secondary traumatization within the family. Protective factors could include internal and external strengths such as strong religious ties, a solid network of friends and family, high self-esteem, and effective coping abilities (Hodge, 2005; Kuehl, 1995).

Jordan's (2004) development of a trauma-based genogram used with war veterans highlights the importance of a militaryspecific genogram that incorporates issues such as combat trauma. Questions that Jordan posed in this genogram included the following: How long was the service member in the war? Did the veteran witness death or injury of others? Were they captured by the enemy? Were they tortured? Such questions are essential in the development of a military genogram because they incorporate war trauma and its effect on family functioning.

\section{Military Culture}

Unlike civilian families, military families represent a unique culture that emphasizes the adherence to specific guidelines 
of conduct. Service men and women conform to a core set of values and traditions inherent in military life. Additionally, military families have the pressure to make a similar commitment to the military's norms, beliefs, and traditions (Drummet, Coleman, \& Cable, 2003; Exum \& Coll, 2008; Exum, Coll, \& Weiss, in press). It is imperative for the clinician to view the person and the family in their prospective environment (Hepworth, Rooney, Rooney, Strom-Gottfried, \& Larsen, 2006). Knowledge of military culture and lifestyle are often foreign concepts for the civilian clinician who might be working with veterans and their families. Therefore, using a military-specific genogram, a clinician can provide culturally sensitive services that include an assessment of protective factors as well as risk factors associated with the military lifestyle and render mechanisms for intervention and resiliency building.

Families are an important part of military life and culture. According to the National Healthy Marriage Resource Center (2006), half of military personnel have families, with an average of two children per service member. Within the military culture, the service member and his or her family exist under a "military umbrella" that is comprised of both strengths and weaknesses, which must be identified and addressed to effectively treat the family unit. There are several branches within the armed forces and there are variations between these branches; however, all service men and women are indoctrinated in military core values that may be viewed as strengths. These values include the following: courage, honor, loyalty, integrity, commitment, mental and physical strength, military mission as a priority, and unit cohesion (Exum \& Coll, 2008; Exum, Coll \& Weiss, in press). Within the context of a military genogram, such strengths could be recognized as viable coping mechanisms and thus be used to enhance resiliency in the family.

However, in addition to military-related strengths, the military culture brings a host of environmental, occupational, psychological, and family stressors. The demands that military service personnel face include the following: multiple deployments (often to combat zones), following a strict chain of command, frequent family separations, the military's stigma toward mental illness (i.e., viewed as a weakness), and a general reluctance toward obtaining mental health services (Matsakis, 2007). Additionally, military families have unique needs and must cope with the effects of the service member's combat-related stress, including PTSD, traumatic brain injuries (TBIs), and/or polytraumatic injuries involving multiple body systems (skin/soft tissue, orthopedic, eye, oral, maxillofacial, ontologic injuries, and complex pain syndromes; Collins \& Kennedy, 2008, p. 993).

In many instances, war-related injuries can result in the service member turning to substance use (often alcohol), partner and familial violence; additionally, the veteran can suffer from mental health issues as a consequence of witnessing war atrocities and experiencing traumatic events, all of which can have a negative impact on the family system. Thus, appropriate mental health care services should not only be provided for the veteran but also for his or her family. In fact, research demonstrates that the well-being and mental health of the military spouse is a predicting factor toward a healthy family unit, soldier retention, and strong armed forces (Gambardella, 2008).

\section{Resiliency}

The term resiliency describes "the process by which people manage not only to endure hardships but also to create and sustain lives that have meaning and contribute to those around them ... resilient individuals are able to draw upon their own internal resources and potential ones in their environment" (Van Hook, 2008, p. 3). Resiliency is a contextual process of successful coping in the face of adversity, risk, or significant change and leads to an individual's sense of selfefficacy, confidence, and a further promotion of resiliency (Stewart, Reid, \& Mangham, 1997; Gutheil \& Congress, 2000; cited in Van Hook, 2008).

According to Fraser, Kirby, and Smokowski (2004; cited in Van Hook, 2008, p. 4), there are three categories of resiliency: (a) "Overcoming the odds," which is having positive outcomes despite a high risk situation; (b) "Sustained competence," which is the ability to cope in a positive manner despite ongoing challenges; and (3) "Recovery from trauma," those that continue to function relatively well after experiencing severely stressful events (e.g., war, violence, and accidents).

Additionally, there are interacting elements such as risk, vulnerability, and protective factors that influence an individual's quality of resiliency (Fraser, Kirby, \& Smokowski, 2004; Greene \& Conrad, 2002; cited in Van Hook, 2008). For example, the literature describes protective factors as buffers to risk factors and that these can be internal to the person (i.e., intelligence, positive outlook, and personality traits), part of the family context (i.e., supportive and loving parents), and the environmental context (i.e., good schools, safe neighborhoods, and opportunities for employment). According to the authors, risk factors are those that increase the likelihood of poor coping mechanisms and negative outcomes; whereas, vulnerability refers to those who are more susceptible to poor coping in the face of crisis events or risk factors.

According to Walsh (1998; cited in Van Hook, 2008), there are three elements that contribute to family resiliency: family's belief systems (i.e., type of meaning making and appraisals of situations), organizational patterns (i.e., degree of flexibility, cohesiveness, and leadership), and communication processes (i.e., ability for open communication, collaborative problem solving, and use of humor); and that these elements are often dictated by the family's social supportive network, cultural prescriptions, community resources, and family history. Van Hook argues that from a resiliency perspective, the clinician needs to be on the constant look out for family strengths. For example, the author poses the following question for clinicians working with families: "What evidence is there in the family history or current context that might have some parallels to the current situation that can be used to enhance the family's sense of self-efficacy and hopefulness regarding their ability to address 
this problem or to identify supports within the family or community?" (p. 86)

\section{Resiliency in the Military Family}

Some of the strengths often associated with a family military lifestyle include the family being provided for by the military (i.e., stable income, housing, and health insurance) and builtin support systems (i.e., Family Readiness Groups, variety of free support groups, and parenting education). Military families are often self-reliant and resourceful; they have a keen appreciation for diversity and global communities and a commitment to a national mission (Rodriguez, 1984; cited in Hall, 2008). Family Readiness Groups offer support to the remaining spouses when the service member is deployed; these are typically led by a Family Readiness Officer, which is often the spouse of an officer who is considered "the point of contact" for other military spouses (Exum, Coll, \& Weiss, in press). Hall (2008) notes that military spouses as a whole demonstrate exceptional strengths such as adaptability, flexibility, willingness to make new friends, loyalty to the service, multitasking abilities, and competent parenting skills (as they often have to become single parent when their spouse deploys). Furthermore, the military's response in promoting the psychosocial well-being of its soldiers and families is through a resiliency building model termed "Battlemind" (Walter Reed Army Institute of Research \& Office of the Surgeon General, Army Medical Command, 2009). Battlemind uses a positive psychology approach to enhance warrior behavioral health in the areas of warrior deployment, life cycle, and support systems.

\section{A Solution-Focused Approach}

In light of the psychosocial issues and the wartime trauma that military families experience, a solution-focused approach within a military genogram is suggested to build resiliency in veterans and in their families. Using a solution-oriented approach assists clients in assessing for risks and barriers while providing a clear lens for the strengths and protective factors that the family and the military culture can provide (Kuehl, 1995). The author adds that without insight into resiliency factors, the likelihood of enacting therapeutic change is diminished.

The solution-focused approach emphasizes a collaborative effort between the client and the clinician on the client's "solutions" rather than on the client's "problems" (De Shazer, 1991). In solution-focused therapy, the exploration of the client's themes occur through the use of questioning, where questions are viewed as "tools for therapeutic interventions" (Berg \& De Shazer, 1993, p. 9). Treatment goals are identified through the use of questioning. Berg and Miller (1992; as cited in Berg \& De Shazer, 1993) outlined several types of questions to be used by the clinician with clients. For instance:

... miracle questions' that help define client goal(s) and illu-
Exception-finding questions, [exploring when a problem did not occur]. Coping questions that highlight the often overlooked but critical survival strategies that clients use in even the most apparently hopeless circumstances and Scaling questions" [number scales used to measure client's perceptions, motivations and confidence]. (p. 9)

Kuehl (1995) combined the use of a genogram with a solutionoriented approach to educate clients about triangulations and intergenerational transmissions of family dynamics. Triangles are comprised of an alliance between two family members against another family member and are often the cause of family dysfunction (Bowen, 1966; Minuchin, 1974; Satir, 1967). Falicov (1998) stated that these alliances are usually composed of "cross generational coalitions" between two members of different generations (i.e., a parent and child against the other parent; p. 37). Kuehl also used narrative interventions to organize and synthesize the transmission of intergenerational family issues including triangulations (Kuehl, 1995). White and Epson (1990) originally described the narrative component in therapy as a "re-storying" of client's lives through a therapist-client collaborative thereby helping the client to recreate meaning out of their experiences and relationships.

A solution-focused model is compatible with the principles of the military culture. The emphasis on solutions rather than problems encapsulates the military's primary tenets of courage, unity, and mental and physical strength. For instance, the therapist and service member can use the genogram to identify potential client barriers such as intergenerational alcoholism and then map out coping mechanisms successfully used by him or her as well as by other family members while simultaneously incorporating the values of military culture. In the case of alcohol use, the military culture can serve as both a protective and a risk factor. Military culture tends to be accepting of drinking, thus, in this way it can be a risk factor; however, negative consequences of drinking, such as being arrested for driving under the influence, can have detrimental effects on military personnel in terms of job security and promotion. Therefore, the military could serve as a deterrent to heavy or irresponsible alcohol use.

Solution focused brief therapy (SFBT) has been shown to be an effective therapeutic approach with military families and children (particularly in the school settings; Sklare, 2005; cited in Hall, 2008). Sklare describes SFBT as espousing the following tenets: An emphasis on client's successes; viewing the client as his or her own expert; every problem having an identifiable exception that can be transformed into a solution; small steps needing to be encouraged and recognized, as these create a ripple effect setting off chain reactions (p. 219). The author adds that a solution-focused approach is a perfect fit in working with a diverse group, such as the military culture, because it uses the client's language, experiences, frame of reference, and seeks solutions that take the military context into account. Wakefield provided the following quote in working with military families: "The responsibility of the [helping] profession is to address things systemically and recognize the 
family and community dynamics of military service ... [the therapist must] understand the depth of trauma to soldiers, their children and their loved ones. It's neglectful not to" (2007; cited in Hall, 2008, p. 221). Ridenour (1984; cited in Hall, 2008) stated that military families often present for counseling due to the conflicts with one another in regard to the demands and stressors placed on them by military service. According to Kuehl, coping questions can be asked by the clinician to guide the client in developing his or her own solutions. One such question could be "Who in your family has dealt with military-related issues and how did they cope with these?" Essentially, the solution-focused approach teaches the client to develop a sense of mastery in their ability to problem solve, based on their own strengths and on their family member's past successes as well as on the hardy nature of the military culture.

\section{A Brief Note About Family Functioning and Cultural Considerations}

Roberto (1992, p. 69) describes a model of a "functional" family or a healthy family system as being comprised of the following: the family is able to cope with important life cycle tasks; the family demonstrates acceptance and nurturance of each individual's needs (especially of the children); an emphasis on the individuation process for each member of the family and the maintenance of boundaries between subsystems; and the family's capacity to tolerate conflict and adapt to adverse circumstances. Many family theorists would agree with some of the fundamentals of family functioning; however, others would argue that delineating strict boundaries around the marital couple is based on Western (American middle class) nuclear family norms and that this may be detrimental in other types of families; thus, one must consider differences in family functioning in terms of ethnicity, race, social class, rural versus urban families (Falicov, 1998). Falicov (1998) added that by promoting strong marital boundaries, in some cultures, the "blocking the participation of other family members may cause strain by undermining other central family ties (Hoffman, 1981) or other potential avenues for conflict resolution" (p. 38). Additionally, some cultures are collectivistic in nature and have gender and generational hierarchies that need to be taken into account whereby separateness and even concepts of individuation would not correspond with the culturally ascribed narrative and world view (Falicov, 1998).

However, another consideration is whether the family's culture is promoting "problem saturated narratives or stories" (Van Hook, 2008, p. 174). The clinician needs to help the family identify cultural messages that relate to gender prescriptions (e.g., boys do not cry) and assist the family in assessing whether these values are helpful to them or not.

\section{Case Vignette}

A military-specific genogram has been created using material from a fictional case vignette. Like most standard genograms, this one includes symbols signifying each family member along with personal characteristics and the relationships that define them (McGoldrick \& Gerson, 1985). Personal characteristics include factors such as religion, ethnicity, age, mental illness, and physical injury. Relational descriptors include commonly used terms in family therapy such as enmeshed or diffused boundaries, estranged or conflictual relationships, and alignments/coalitions (i.e., triangulations; Bowen, 1966; Minuchin, 1974; Satir, 1967). See Figures 1 and 2. For a more detailed explanation of family therapy concepts, the reader is encouraged to refer to the above authors.

Deborah Mangiagli, a 37-year-old Jewish woman of Russian-Polish descent, who came into the private office of a clinical social worker, complaining of "turmoil" within her family environment. Deborah states that her husband, Joseph Mangiagli a 38-year-old Italian Irish American Field Officer in the U.S. Army, has recently returned from a tour of duty in Afghanistan. Joseph has been deployed four times since he joined the Army. Deborah states that her husband appears angry and is isolative from her and the children. During the day, she reports, that he "isolates himself" and "overreacts to the smallest things." Deborah recalls that on several occasions, she is woken up at night by her husband pacing around the room, holding a pillow tightly to his chest. One evening, her husband revealed to her that he was having difficulty with sleep due to recurrent nightmares of his best friend's brutal attack by insurgents. He also frequently dreams about the explosion from the Intermittent Explosive Device (IED), which occurred while traveling across the desert in a Humvee that killed several of his soldiers. She has noticed that it is often difficult for her husband to speak without stuttering, he exhibits memory problems, and he has frequent explosive outbursts. Both their son and their daughter feel like they are "walking on eggshells" around him and therefore have avoided inviting friends over to the house.

Deborah and Joseph live in family housing on an Army base and have been married for 5 years. Deborah's first husband, Larry, a firefighter, died on September 11, 2001, when two hijacked jetliners hit the world trade center. After 2 years of grieving, Deborah met her second and current husband, Joseph, prior to his second deployment to Iraq. In 2005, Joseph and Deborah wed, each bringing a child into the union. Deborah reports that she often loses sleep at night, worrying that she will lose another husband to the war on terror. She finds solace in her local synagogue, volunteering at the gift shop, and has made friends through her religious affiliation as well as with some other military wives.

Nicole, Joseph's biological daughter, is 15 years old. She has not seen her biological mother, Linda, in 10 years due to her mother's heroin dependence and subsequent incarceration. Nicole had been living with her paternal grandmother, Dorothea, but the relationship was becoming strained because of Nicole's acting out behaviors (e.g., engaging in drug use, promiscuity, and oppositional behavior). Since her father returned from Afghanistan, Nicole has moved into the family home; however, she has never accepted Deborah as a stepmother and complains that Deborah favors her biological son David over her. Deborah feels frustrated by Nicole's behaviors and has little 


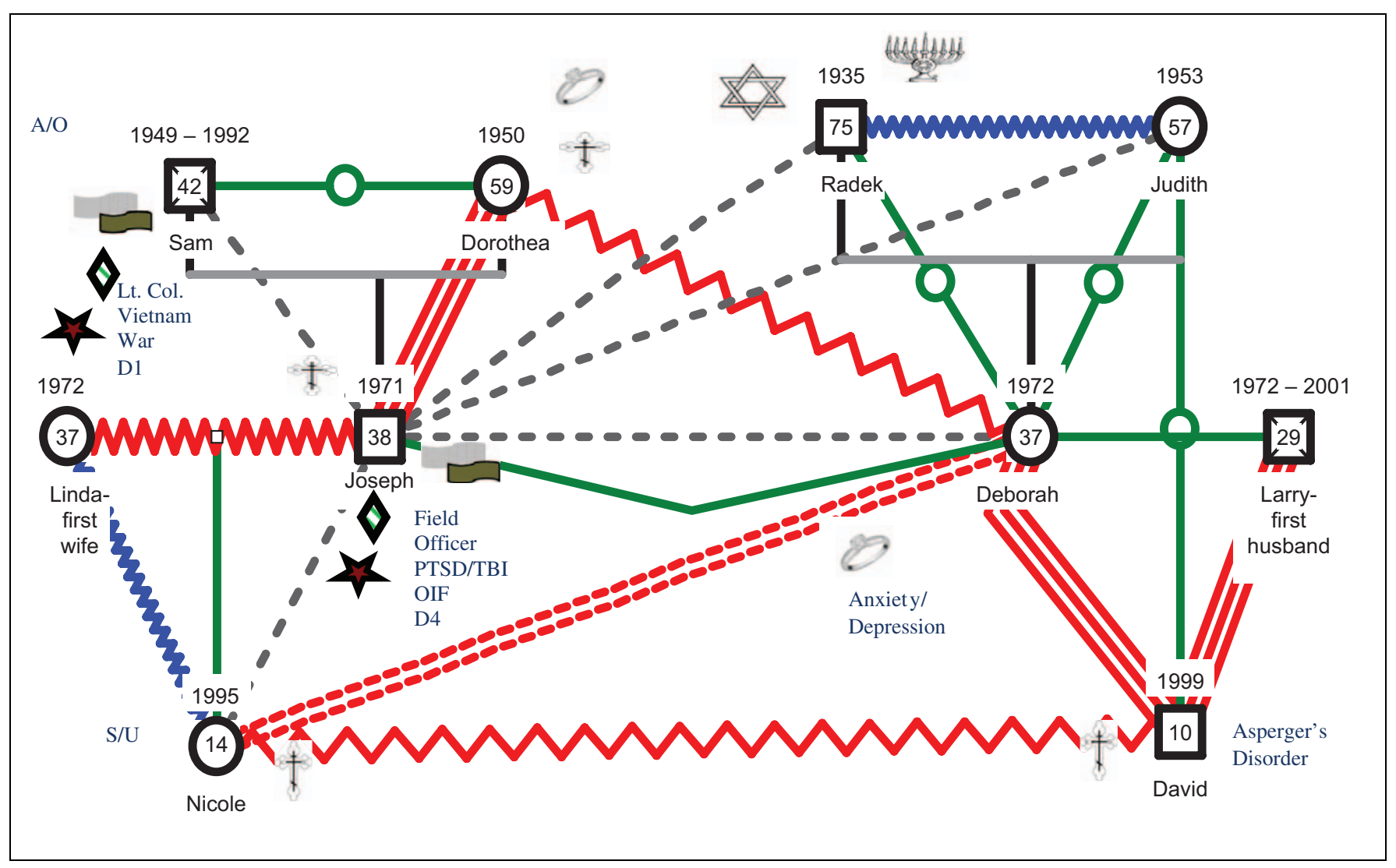

Figure I. The Mangiagli family genogram.

patience for her and she feels that her husband sides with Nicole against her. Deborah and Joseph frequently argue about Nicole. Deborah states that her stepdaughter "would abuse mouthwash if that was the only thing available to her and that her father defends her at all costs." Nicole frequently sneaks of the house out at night where she meets up with boys in the neighborhood. However, Nicole is an avid reader and enjoys writing poetry, which has resulted in her getting writing awards and recognition for her talents at school. Deborah has some difficulty expressing her pride in Nicole's accomplishments.

Deborah has a 10-year-old son named David who was diagnosed with Asperger's disorder at 4 years of age. He has difficulty developing peer relationships and engages in repetitive patterns of behavior. Deborah states, "He knows every dinosaur that has ever existed including height, weight, and eating patterns. I just wish he could make friends." Nicole and David do not get along and engage in frequent arguments. Deborah reports, "I feel bad that I always side with David, but he has a disability and Nicole does not."

Deborah's family of origin resides out of state in New York. She calls them at least three times a week and e-mails them daily. She feels that her parents are a source of support for her. Deborah's father, Radek, is a Polish American Jew. He grew up in Poland during the Nazi occupation and was a "hidden child" during the Holocaust. Radek has suffered from flashbacks, anxiety, and anger all of his life. According to Deborah, during the first 20 years of her parents' marriage, her father was emotionally abusive toward her mother and was suspected of having multiple affairs. However, over time, their relationship has improved significantly. Deborah's mother, Judith, is a Russian American Jew, whose family was persecuted by the Pogroms in the early 1900 s and subsequently they immigrated to the United States. Deborah has a close relationship with her mother and has learned through her mother that Judaism provides a strong source of strength and solace for the family. Both of her parents were not especially supportive of Deborah's second marriage to a soldier and they are against the war in the Middle East.

Joseph's father, Sam, died of leukemia when Joseph was 21 years old. Sam was of Italian Irish descent and served in the Vietnam War from 1966 to 1972 as a Lieutenant Colonel in the Army. He was wounded by a bullet to his leg and was honorably discharged. Once returning from Vietnam, he showed symptoms of combat stress as he woke up from nightmares screaming, withdrew from social interaction, and drank excessively, especially the first few years after he returned from Vietnam (but was able to maintain sobriety for the last few years of his life). His physicians from the V.A. believed that he was exposed to Agent Orange, which may have caused his Leukemia. Joseph loved his father while growing up; however, he wished he could have "connected" with him more. Joseph joined the military as a means of gaining acceptance from his 


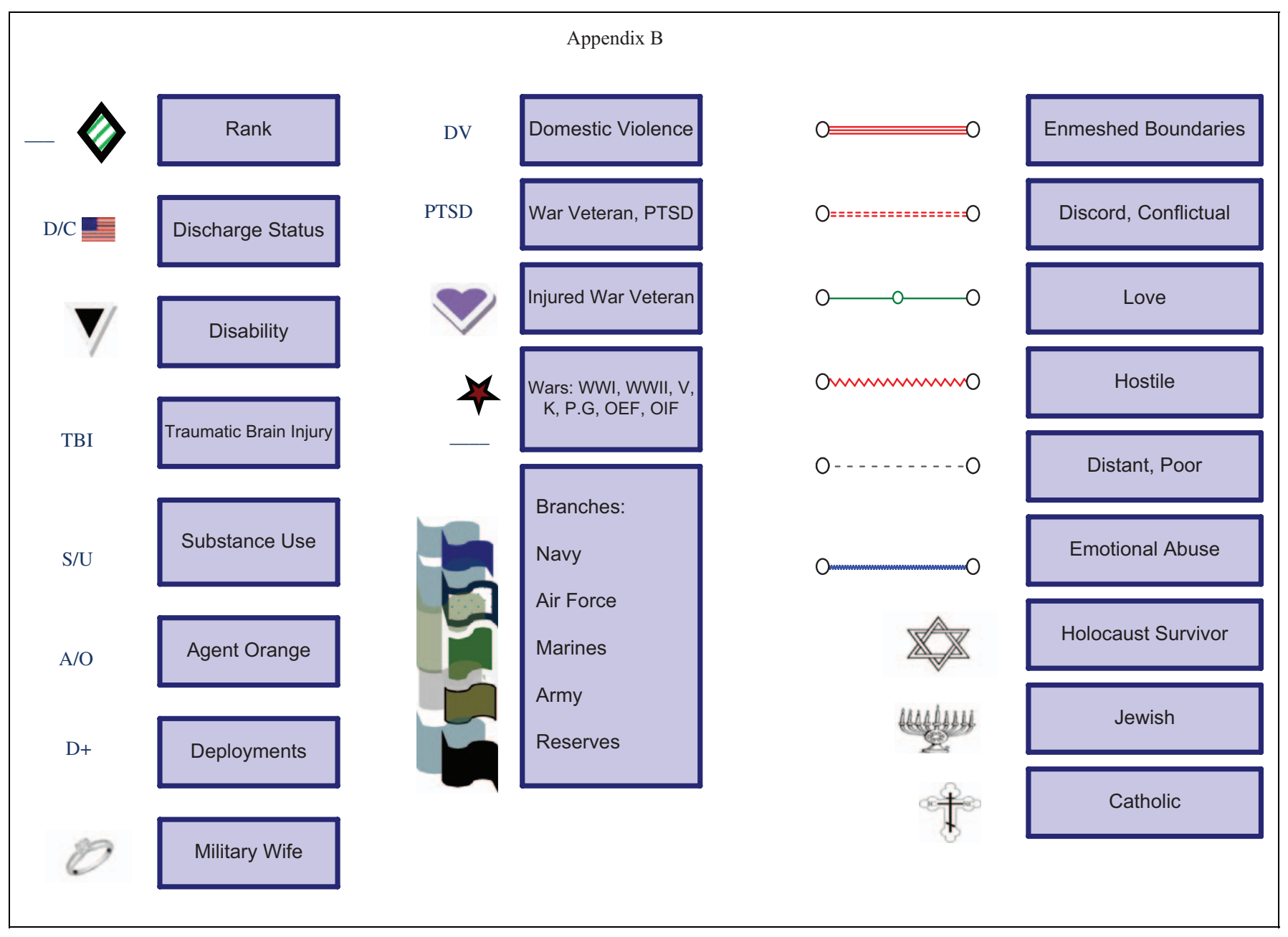

Figure 2. Genogram key.

father. Joseph was overwhelmed with joy when his father expressed pride over his military achievements. Joseph still carries the guilt that he was overseas the day his father passed away.

Joseph's mother, Dorothea, is a devout Catholic of Italian descent. Deborah gets frustrated with Dorothea because she often comes to their home unannounced and feels that she is intrusive. Dorothea lectures Deborah on how to properly raise her children in a Catholic home and on how to be a "good wife" to her son. Dorothea believes her son, Joseph, "can do no wrong," which further isolates Deborah. Deborah is further angered by her husband, because she feels that Joseph does not stand up to his mother. Both Dorothea's father and grandfather were high-ranking officers in the army during her childhood and young adulthood. Dorothea shows little patience for Deborah's "weakness" as a military wife and often tells her to "toughen up."

Deborah feels overwhelmed with the mounting responsibilities since Joseph returned from the last deployment. She is disappointed that her husband has not been actively engaged in family life. She is thankful, however, that her husband has not turned to alcohol or other substances as means of coping. Joseph witnessed years of his father's excessive drinking and vowed he would never repeat the cycle of abuse. Deborah, however, is concerned that Joseph's increase in social drinking with his "work buddies" may eventually turn into problem drinking. She recently gave him an ultimatum to attend marital therapy or that they would separate. He reluctantly agreed to go for couples counseling.

\section{Discussion of Vignette}

A military-specific genogram coupled with a solution-focused strategy provides a strengths-based approach in the identification of family and relational patterns while bolstering resiliency and aiding in the construction of relevant family interventions. A brief discussion of the application of the military genogram to the case vignette will be presented.

A clinician must begin with a comprehensive assessment of the service member and his or her family. The questions provided in Table 1 can be used by the clinician to construct a standard genogram. The clinician must be thoughtful in tailoring the questions to each client and family member and doing so in an appropriate manner. Some of the questions are for the clinician to consider as he or she is conceptualizing the case 
Table I. Basic Genogram Questions for Clinician Consideration

Who are the family members and their composition (names, ages, and occupation)?

Are there any biological/step relationships? If so, what are their relationships like? (disrupted, enmeshed, triangulated, etc.)

What are the presenting problems?

Who is the identified client?

Who is the scapegoat of the family? The family hero?

What are the power dynamics between family members? How do the parents exert power in the household?

What are the dynamics of the marriage? How does it impact the remainder of the family?

What are the jobs (roles) of the adult members of the family? How do they impact family functioning and relationships?

What are the risk factors in the family with regard to health concerns, substance abuse, mental illness, child abuse, domestic violence, TBI, suicide and/or homicide ideation and previous history of attempts?

Identify who is married, divorced or separated (and length of time). Have there been any infidelities?

Are there any family members that have died? Of what? If so, how has it affected family dynamics?

Identify the family relationships (alignments, estrangements, conflictual relations, strengths of relationships)

Identify the following for each family member: culture, religion, spirituality, sexual orientation.

Do any of the family members deviate from the cultural, spiritual or sexual orientation norms of the family? If so, how has it impacted the family dynamics?

What are the gender roles defined among family members?

What is the socioeconomic status of the family? Does SES have an impact on family dynamics?

Is there a history of trauma in the family? Transgenerational trauma?

Do any family members have an addiction? If so, have they been treated? How frequently do they use? Are there any risk/medical factors associated with the use?

Note. SES = socioeconomic status; $\mathrm{TBI}=$ traumatic brain injury.

and are not necessarily to be used directly with the client (e.g., by asking the family who is the scapegoat?) Questions from Table 1, which can be used directly with clients include What are the presenting problems? Is the family a blended family (i.e., step relationships)? If so, what are their relationships like? What are the roles of each of the family members? How do these roles impact family functioning and relationships? Gambardella (2008) states that changing family roles are an important issue to address with military families. Furthermore, the stages associated with deployment stressors (from predeployment, deployment, sustainment, redeployment, and post-deployment phases) present challenges to the family in terms of continuous role adaptations that occur with each phase (Pincus, House, Christenson, \& Adler, n.d.). These adaptations are best conceptualized by role-exit theory, defined as the "departure from any role that is central to one's self identity" (Ebaough, 1988; cited in Gambardella, 2008, p. 170).

In the case of the Mangiagli family, Deborah's presenting problem is her feeling overwhelmed with her multiple roles (i.e., wife, mother, and caretaker). She may be experiencing "caregiver burden" as a result of her husband's volatile behaviors and limitations since his return from the last deployment, her managing household duties, and the stress associated with caring for a disabled son and an adolescent stepdaughter. Her goals are to reintegrate her husband back into the family as he has been disengaged since his return from Afghanistan and to manage her multiple roles more effectively as well as improve her relationship with her stepdaughter. It would be important for the clinician to help Deborah develop some empathy for Nicole's losses (i.e., a cutoff relationship with her incarcerated mother, the recent strained relationship with grandmother, moving from her grandmother's home, and an emotionally and physically unavailable father). It would also be important to highlight Nicole's strengths, such as her creative talents. The clinician should also work with the couple to strengthen their hierarchical structure as parents and as spouses and diffuse the triangulation between the parentdaughter dyad (Joseph-Nicole) and between Joseph and his mother. The coalition between Joseph and his mother would need to be considered carefully as his mother has played an integral role in parenting Joseph's daughter and from a cultural perspective, the Italian family is very tightly knit and the matriarch plays a large role in the family. Thus, the therapist would have to tread carefully around this area. The clinician would also need to help the couple understand that triangulation between Joseph and Nicole is means of avoiding their own marital discord. Furthermore, Nicole may be at risk for emotional abuse or neglect by Deborah and it would be important to make the connection for Deborah, that Dorothea is behaving similarly toward Deborah, as Deborah is toward Nicole, with little patience or empathy. Additionally, Deborah may be more susceptible to domestic violence, because she grew up in a home where her father was emotionally abusive toward her mother and her father had posttraumatic stress and thus she may be reexperiencing secondary traumatization (first from her father and now from her husband). It would be essential to point out the intergenerational transmission of trauma. It would be imperative for the clinician to help the family see the generational connections and examine how these could be risk factors as well as sources of strength. Some family strengths on Deborah's side include Radek's ability to survive as a hidden child during the Holocaust; Radek's and Judith's resilience in their marriage, despite serious challenges and how they were able to overcome their difficulties; as well as Judith's faith and the role it has played in her ability to cope with life circumstances. 
Table 2. Added Elements for a Genogram With Military Families

Assess family history of: military service, rank, length of service, honors, discharge status, nature of discharge.

What is the immediate family's attitude toward the military?

What is the extended family's attitude toward the military?

What is the family's cultural attitude toward military service? Attitude toward war?

Were the military family members drafted or did they volunteer?

Have the service family members served during a time of war? If so, when? What war?

Have the military family members ever experienced wartime trauma? If so, what? Has it affected their functioning? And if so, how?

What of the following incidents have the service members' experienced and/or witnessed: casualties, injuries, disabilities, prisoner of war, AWOL.

Did the service member lose friends or comrades in a war? If so, how many? What were the circumstances?

What is the level of self-disclosure about range of the military experiences for the service member?

What is the attitude toward mental health treatment or view of emotional illness?

Does the service member have a drinking/drug problem? If so, was it a problem prior to deployment?

Does the service member utilize military-extended networks or VA services?

What was the service member's role prior to deployment? Has it changed post-deployment?

What are the family members' political affiliations?

Does the family live on base or off base?

What is the current sociopolitical climate and how does it impact the family?

Joseph appears to be experiencing symptoms of PTSD as reflected by his insomnia and midnight pacing, his hypervigilance, recurrent nightmares, and flashbacks of his combat experiences. Of significance, Joseph's father suffered from similar symptoms of posttraumatic stress due to his service in the Vietnam War. Consequently, the clinician again must be aware of the impact of intergenerational trauma and educate the clients on how it affected them as they were growing up and how it can be potentially passed down to their children. In addition, the clinician would need to point out that based on his father's alcoholism Joseph may be at risk for problem drinking. However, at the same time, be able to discuss how his father was able to stop drinking in the face of very stressful events, including a serious medical illness. It would be relevant to also point out Dorothea's strengths in coping with her husband's alcoholism, medical problems, and then becoming a widow. She also become a single parent to a young granddaughter and has always been there for her family. Dorothea's family history of military service has also been a source of strength in helping her cope and understand military life.

Additionally, it would be prudent to discuss with the family that as Deborah and Joseph have recently formed a blended family, their stressors may be compounded due to the adjustment of new roles and rules within the family unit. Like many blended families, the Mangiaglis are experiencing roleconfusion and difficulty maintaining healthy boundaries. First, Deborah seems to be struggling with her role as a stepmother to Nicole and does not feel comfortable providing appropriate consequences to her acting out behaviors nor is she attempting to build a positive relationship. Second, Joseph may be confused about his role in family as he spent time away from the family due to his deployment and Deborah had been managing the household and parental responsibilities. In addition, Joseph may be limited in his parenting capacity at this time due to his post-deployment adjustment problems and stress. Third, Nicole is angered by Deborah's newfound role as "mother." Nicole appears to be experiencing frustration in her new roles as stepsister and stepdaughter. Her difficulty adjusting to these roles and lack of understanding and support from her parents, may explain, in part, her acting out behaviors.

In addition to assessing for family roles and boundaries, the clinician may use the genogram to assess for additional risk factors. The primary risk factors of the Mangiagli family include the potential for child abuse, suicide, domestic violence, and TBI. Joseph is experiencing difficulty managing his angry outbursts and as a result, the children sometimes fear him. Consequently, child abuse and domestic violence must be continuously assessed. In addition, Joseph experienced an IED blast, which may have caused TBI (especially as he reports trouble with memory). It is important for the clinician to assist the family in ruling out TBI as it could compound the diagnosis of PTSD. A medical referral should be provided. Although Joseph has not expressed overt suicide ideation, he should be continuously monitored due to his somewhat depressive symptoms and isolation.

The clinician may use the military genogram questions from Table 2 to establish an understanding of the family's perception of military culture and lifestyle. It is essential for the clinician to understand the family's view of the military service and the clinician's own biases toward the military and countertransference issues that could influence the dynamics of the sessions. Hence, the following questions from Table 2 could be used to construct the genogram and to understand military culture as it relates to the family: What is the client's attitude toward mental health services? Does the family live on base? What is the level of self-disclosure of the military service member regarding his wartime experiences? Did the service member witness or experience traumatic events? What is the family's and the extended family's members attitudes toward the military? How do these attitudes impact individual or family functioning? These military genogram assessment questions were selected to educate the clinician on how the family perceives 
Table 3. Clinical Questions for Further Consideration and Solution-Focused Related Questions

What provisional diagnoses would we give the Identified Client? Other family members?

What symptoms support these diagnoses?

Are there any differential diagnoses that could be made?

What theoretical framework would we draw from to understand the family?

Where do we begin the genogram assessment interview? At what point do we begin treatment?

What would an initial treatment plan look like?

Are there any factors the social worker should take into consideration with regard to beginning treatment with the military family?

What are the family protective factors that will assist in treatment?

What are the family barriers that could hinder treatment?

Does the family exhibit resiliency factors? If so, what are these? How can resiliency factors be used effectively in treatment?

What type of interventions would we consider for the family? What entry point in treatment would you utilize or, what subsystem would you begin working with (i.e., identified patient [IP], couple, and family)

What resources/referrals could be utilized?

What are the family members' strengths?

Are there any specific military-related resources/referrals that would be particularly helpful for the military family?

What is the prognosis for therapy?

How have you managed to deal with your problems? How did other members cope with their problems?

Considering your family history and your current relationships, what would improvements would you like to make?

How have you worked to improve your current situation?

How do you currently cope with your problems? How is that different than how your family members coped?

How have you managed to diffuse the problems in your life?

What do you think the problem is now? How will you know if the problem is solved? What would be different? (basis of the miracle question)

How motivated are you to solve your problem? (from a scale of $\mathrm{I}-10$ )

How serious is your problem? (from a scale of $\mathrm{I}-\mathrm{I} 0$ )

How confident are you that you can solve the issue? (from a scale of $1-10$ )

Has there been a time when the issue that brought you to therapy was not present, or it was less intense or handled by you in a way that made you feel better?

the military and the impact of military service on the family as well as the impact of military generations within the family.

The clinician should be sensitive toward the service member's feelings regarding mental health services. In the case of the Mangiagli family, it can be assumed that Joseph may perceive mental health services as a sign of weakness. This is exhibited by Joseph's initial response toward Deborah's request to attend therapy. Traditionally, the culture of the military perceives mental health services as a weakness (Exum, Coll, \& Weiss, in press). Consequently, it is important for the clinician to assess and address this important issue, as it could affect the effectiveness of services.

The values of the military culture are to be courageous and to show no signs of weakness, which may be further reinforced by living on base. As Joseph lives on base with his comrades, he may be less motivated to self-disclose his experiences in the war to his wife because it conflicts with basic military ideology. Also, living on base, in close quarters with other families, there is often some fear of privacy issues and confidentiality, as neighbors often talk to one another. Joseph's reluctance to reveal traumatic experiences may be further compounded by his desire to avoid exacerbating his PTSD symptoms. Joseph experienced two significant and traumatic experiences during his deployments. The loss of his comrade to enemy insurgents and a fatal IED explosion have likely affected his level of trust in himself and in his environment and this has affected his ability to intimately connect with his wife and children. Therefore, it is important for the clinician to use sensitivity and open-ended questions in assessing for the service member's ability to discuss traumatic events.

Another factor that may be influencing Joseph's reluctance to share wartime experiences with his family could be how his family perceives his military service. The social interactions of extended and nuclear family members could contribute to family scripts. For example, Dorothea was raised in a military family and her husband was a lieutenant in the Vietnam War. Thus, Joseph's family is supportive of the military lifestyle and lives by traditional family values, such as always being courageous. Conversely, Deborah's family originates from the Jewish Holocaust and they are pacifists. Joseph may be concerned about how his wife perceives him if he shares his deployment experiences. Clearly, the military genogram assists the clinician in discriminating between the perceptions of family members regarding military lifestyle. This is of particular importance as the varying perceptions of the military likely influence familial relationships, as shown in the vignette.

Questions from Table 2 guide the clinician in understanding the military experience through the service member's perceptions and those of his family. However, questions derived from Table 3 will assist the clinician in recognizing the client's protective factors while developing a solution-focused approach to treatment (many of the questions are borrowed from the solution-focused literature). The following questions should always be asked with every military family to use a strengthsbased perceptive: What are the family member's strengths? What are the resiliency factors of family members? How do 
these factors influence family functioning? How have other family members coped with similar experiences, and How did they overcome challenges?

Within the context of the vignette, individual family members and the family unit exhibited multiple strengths that may be used for treatment planning. Some additional strengths in the Mangiagli family, which are worthy of discussion include the following. First, Deborah was able to raise her son despite the traumatic and premature death of her husband. The clinician may evaluate the strengths of previous generations and point out that Deborah's father exhibited similar strengths due to his survival of the Holocaust. Furthermore, Deborah is relationally close with her mother and to her extended family that provides her with support despite living geographically apart.

Second, Joseph exhibits significant strengths as he possesses the ability to persevere through traumatic wartime experiences and not use harmful coping mechanisms. Joseph grew up with an alcoholic father; however, he has not turned to drinking to cope with his feelings (although he may be at risk). Joseph is also willing to attend therapy despite the stigma that is often associated with receiving mental health services. As a result, Joseph reflects significant resiliency. The clinician should understand his military values as strengths as they have contributed to adaptive behaviors.

The family as a unit also possesses strengths. It can be assumed that because Joseph is a Field Officer in the Army, the family's socioeconomic status is higher and they do not have to worry significantly about financial concerns. Deborah is also home with the children, which is also a source of strength for the family. Additionally, while military culture may view mental health services as a weakness, the value of perseverance in the military will assist the family in fighting to improve their lives and overcome barriers. Evidently, the clinician must demonstrate to the family through the use of the genogram, the family's adaptive behaviors, and ability to positively cope with distressing events. Finally, it is essential to include solution-focused questions from Table 3 to assist the military family in developing their treatment goals for therapy and that the questions in their own right are valuable methods of intervention.

\section{Conclusion}

The military genogram is an effective tool to be used in clinical practice with military personnel and their families for therapeutic rapport building and providing culturally sensitive assessment and intervention services. The military lifestyle encompasses specific virtues, ethics, rules, and values that differentiate it from civilian society. Therefore, it is imperative for the clinician to develop a competency in working with the military population as distinct culture.

From a solution-focused perspective, the clinician works in collaboration with clients, highlighting strengths that can enhance resiliency and self-efficacy and therefore contribute to improved individual and family functioning and wellbeing. Thus, the combination of a strengths perspective with an appreciation of the impact of military culture will render the most effective and complementary approach in working with service members and their families. Helpful and successful treatment ultimately translates into better equipped soldiers to defend our nation and increased adaptability for veterans and families to transition into the civilian world.

\section{Declaration of Conflicting Interests}

The authors declared no potential conflicts of interests with respect to the authorship and/or publication of this article.

\section{Funding}

The authors received no financial support for the research and/or authorship of this article.

\section{References}

Berg, I. K., \& De Shazer, S. (1993). Making numbers talk: Language in therapy. In S. Friedman (Ed.), The new language of change: Constructive collaboration in psychotherapy (pp. 5-24). New York, NY: Guilford.

Bowen, M. (1966). Family therapy in clinical practice. Northvalle, NJ: Jason Aronson.

Collins, R. C., \& Kennedy, M. C. (2008). Serving families who have served: Providing family therapy and support in interdisciplinary polytrauma rehabilitation. Journal of Clinical Psychology, 64, 993-1003.

Dekel, R., \& Goldblatt, H. (2008). Is there intergenerational transmission of trauma? The case of combat veterans' children. American Journal of Orthopsychiatry 78, 281-289.

De Shazer, S. (1991). Putting differences to work. New York, NY: Norton.

Drummet, A. R., Coleman, S. R., \& Cable, S. (2003). Military families under stress: Implications for family life education. Family Relations, 52, 279-287.

Duba, J. (2009). Introducing the "basic needs genogram" in reality therapy-based marriage and family counseling. International Journal of Reality Therapy, 29, 15-26.

Exum, H., \& Coll, J. E. (2008). A Civilian Counselor's Primer for Counseling Veterans. Deerpark, NY: Linus Publications.

Exum, H., Coll, J. E., \& Weiss, E. L. (in press). A Civilian counselor's primer for counseling veterans (2nd ed.). Deerpark, NY: Linus Publications.

Falicov, C. J. (1998). The cultural meanings of family triangles. In M. McGoldrick (Ed.), Re-visioning family therapy: Race, culture, and gender in clinical practice (pp. 37-49). New York, NY: Guilford.

Foster, M. A., Jurkovic, G. J., Ferdinand, L. G., \& Meadows, L. A. (2002). The impact of the genogram on couples: A manualized approach. The Family Journal: Counseling and Therapy for Couples and Families, 10, 34-40.

Frame, M. W. (2000). The spiritual genogram in family therapy. Journal of Marital and Family Therapy, 26, 211-216.

Gambardella, L. C. (2008). Role-exit theory and marital discord following extended military deployment. Perspectives in Psychiatric Care, 44, 169-174. 
Granello, D., Hothersall, D., \& Osborne, A. (2000). The academic genogram: Teaching for the future by learning from the past. Counselor Education and Supervision, 39, 177-188.

Hall, L. K. (2008). Counseling military families: What mental health professionals need to know. New York, NY: Routledge.

Hardy, K. V., \& Laszloffy, T. A. (1995). The cultural genogram: Key to training culturally competent family therapists. Journal of Marital and Family Therapy, 21, 227-237.

Hepworth, D. H., Rooney, R. H., Rooney, G. D., Strom-Gottfried, K., \& Larsen, J. A. (2006). Direct social work practice: Theory and skills (7th ed.). Pacific Grove, CA: Thomson Brooks/Cole.

Hodge, D. (2005). Spiritual ecograms: A new assessment instrument for identifying client's strengths in space and across time. Families in Society, 86, 287-296.

Jordan, K. (2004). The color-coded timeline trauma genogram. Brief Treatment and Crisis Intervention, 4, 57-70.

Kakiuchi, K., \& Weeks, G. R. (2009). The occupational transmission genogram: Exploring family scripts affecting roles of work and career in couple and family dynamics. Journal of Family Psychotherapy, 20, 1-12.

Karin, J. (2006). The scripto-trauma genogram: An innovative technique for working with trauma survivors' intrusive memories. Brief Treatment and Crisis Intervention, 6, 36-51.

Keiley, M., Doblin, M., Hill, J., Karuppaswamy, N., Liu, T., Natajan, R., \& . . Robinson, P. (2002). The cultural genogram: Experiences from within a marriage and family therapy training program. Journal of Marital and Family Therapy, 28, 165-178.

Kuehl, B. P. (1995). The solution-oriented genogram: A collaborative approach. Journal of Marital and Family Therapy, 21, 239-250.

Magnuson, S. (2000). The professional genogram: Enhancing professional identity and clarity. The Family Journal, 8, 399-401.

Matsakis, A. (2007). Back from the front: Combat, trauma, love, and the family. Baltimore, MD: Sidram Institute Press.
McCullough-Chavis, A., \& Waites, C. (2004). Genograms with African American families: Considering cultural context. Journal of Family Social Work, 8, 1-17.

McGoldrick, M., \& Gerson, R. (1985). Genograms in family assessment. New York, NY: Norton.

Minuchin, S. (1974). Families and family therapy. Cambridge, MA: Harvard University Press.

Mumford, D., \& Weeks, G. (2003). The money genogram. Journal of Family Psychotherapy, 14, 33-44.

National Healthy Marriage Resource Center. (2006). Research based answers to frequently asked questions about military service and marriage. Retrieved from www.healthymarriageinfo.org

Pincus, S. H., House, R., Christenson, J., \& Adler, L. (n.d.). The emotional cycle of deployment: A military family perspective. Retrieved from http://hooah4health.com/deployment/familymatters/emotionalcycle.htm

Roberto, L. G. (1992). Transgenerational family therapies. New York, NY: Guilford.

Satir, V. (1967). Conjoint family therapy. Palo Alto, CA: Science and Behavior Books.

Selma, Y. (2008). Using the genogram to facilitate the intercultural competence of Mexican immigrants. The Family Journal, 16, 159-165.

Shellenberger, S., Dent, M. M., Davis-Smith, M., Seale, J. P., Weintraut, R., Wright, T. (2007). A cultural genogram: A tool for teaching and practice. Families, Systems \& Health 25, 367-381.

Sylvia, S., Marie, D., Monique, D., Paul, S., Weintraut, R., \& Tamara, W. (2007). Cultural genogram: A tool for teaching and practice. Families, Systems and Health, 25, 367-381.

Van Hook, M. P. (2008). Social work practice with families: A resiliency-based approach. Chicago, IL: Lyceum Books.

Walter Reed Army Institute of Research, \& Office of the Surgeon General, Army Medical Command. (2009). Battlemind. Retrieved from www.battlemind.army.mil

White, M., \& Epston, D. (1990). Narrative means to therapeutic ends. New York, NY: HarperCollins. 